\title{
Recovery Plan for Ord's Kangaroo Rat in Alberta
}
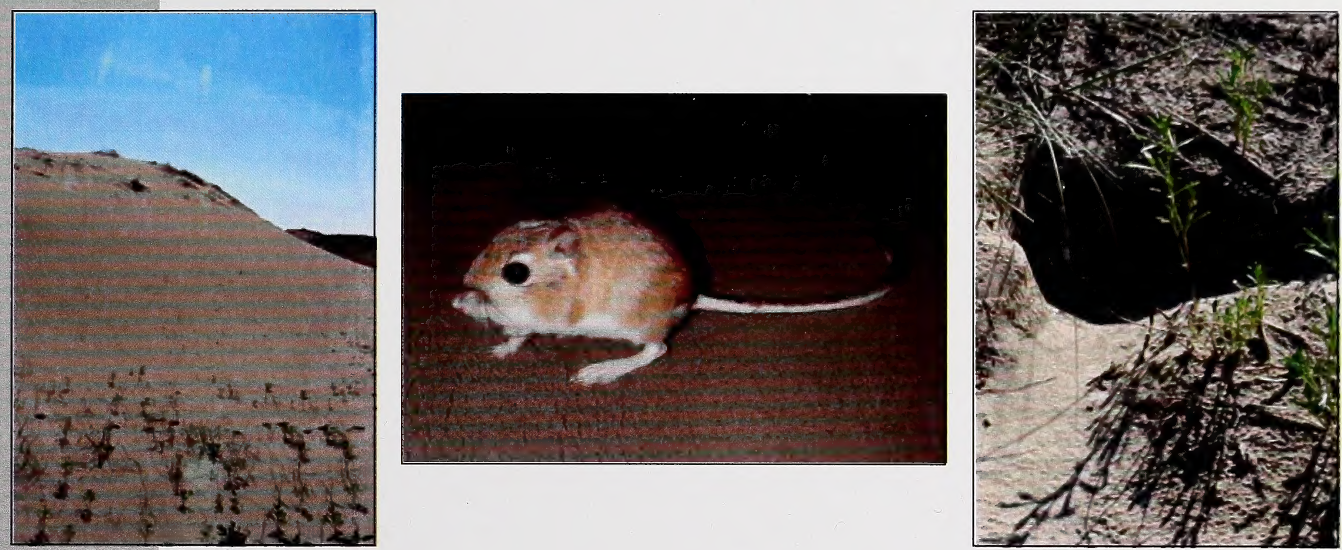

Alberta Species at Risk Recovery Plan No. 5 
Digitized by the Internet Archive in 2016 


\section{Recovery Plan for Ord's Kangaroo Rat in Alberta}

\section{Prepared by:}

The Alberta Ord's Kangaroo Rat Recovery Team

Arlen Todd (Team Leader, Co-chair), Alberta Fish and Wildlife Division Brent Smith (Co-Chair), Canadian Forces Base Suffield

Darren Bender, University of Calgary

Delaney Boyd, Canadian Forces Base Suffield

Bill Bristol, Prairie Farm Rehabilitation Administration

Dan Davies, Oil and Gas Industry

Dale Eslinger, Alberta Fish and Wildlife Division (ex-officio)

David Gummer, Royal Alberta Museum

Kelley Kissner, Alberta Fish and Wildlife Division

Gerald Kornelson, Rancher

Dug Major, Special Areas Board

Hal Reynolds, Canadian Wildlife Service

December 2005

\section{Alberta}


Publication No. I/228 (Printed, On-line edition)

ISBN: 0-7785-4509-1 (Printed Edition)

ISBN: 0-7785-4510-5 (On-line Edition)

ISSN: 1702-4897 (Printed Edition)

ISSN: 1702-4900 (On-line Edition)

Cover photos: David L. Gummer, Royal Alberta Museum, copyright 2005

For copies of this report, contact:

Information Centre - Publications

Alberta Sustainable Resource Development

Main Floor, Great West Life Building

9920 - 108 Street

Edmonton, Alberta, Canada T5K 2M4

Telephone: (780) 422-2079

\section{OR}

Visit the Alberta Species at Risk web site at:

http://www3.gov.ab.ca/srd/fw/speciesatrisk/index.html

This publication may be cited as:

Alberta Ord's Kangaroo Rat Recovery Team. 2005. Recovery plan for Ord's kangaroo rat in Alberta. Alberta Sustainable Resource Development, Fish and Wildlife Division, Alberta Species at Risk Recovery Plan No. 5. Edmonton, AB. 28 pp. 


\section{PREFACE}

Albertans are fortunate to share their province with a diverse variety of wild species.

Populations of most species of plants and animals are healthy and secure. However, a small number of species are either naturally rare or are now imperilled because of human activities. Recovery plans establish a basis for cooperation among government and stakeholders to ensure these species and populations are restored or maintained for future generations.

Alberta's commitment to the Accord for the Protection of Species at Risk and to the National Framework for the Conservation of Species at Risk, combined with requirements established under Alberta's Wildlife Act and the federal Species at Risk Act, has resulted in the development of a provincial recovery program. The overall goal of the recovery program is to restore species identified as Threatened or Endangered to viable, naturally self-sustaining populations within Alberta.

Alberta species at risk recovery plans are prepared under the supervision of the Fish and Wildlife Division, Alberta Sustainable Resource Development. These recovery plans are prepared by recovery teams composed of a variety of stakeholders including conservation organizations, industry, landowners, resource users, universities, government agencies and others. Membership is by invitation from the Director of Wildlife Management, and includes representation from the diversity of interests unique to each species and circumstance. Conservation and management of these species continues during preparation of the recovery plan.

Recovery plans include three main sections: background information that highlights the species' biology, population trends and threats; a recovery section that outlines goals, objectives, and strategies to address the threats; and an action plan that profiles priority actions required to maintain or restore the Threatened or Endangered species.

These plans are provided by the recovery team as advice to the Minister of Sustainable Resource Development (the Minister; the Department) and to all Albertans. The Department, other provincial departments, as appropriate, and Alberta's Endangered Species Conservation Committee review draft recovery plans, and provide recommendations to the Minister. In addition, an opportunity for review by the public is provided.

Approved plans are a summary of the Department's commitment to work with involved stakeholders to coordinate and implement conservation actions necessary to restore or maintain these species. Recovery plans are "living" documents and are revised as conditions change or circumstances warrant. Implementation of each recovery plan is subject to the availability of resources, from within and from outside government.

The Recovery Plan for Ord's Kangaroo Rat in Alberta was reviewed by the Endangered Species Conservation Committee in March 2005. The committee subsequently recommended to the Minister that the plan be approved as written, and implemented. On December 16, 2005, the Minister approved the recovery plan and directed the Department to adopt and implement the plan. 


\section{TABLE OF CONTENTS}

PREFACE iii

LIST OF FIGURES vi

LIST OF APPENDICES vi

ACKNOWLEDGEMENTS vii

EXECUTIVE SUMMARY viii

1.0 INTRODUCTION

1.1 Provincial and National Status

1.2 Recovery Team

2.0 SPECIES' BIOLOGY

2.1 Life History and Adaptations

2.2 Habitat 3

2.3 Population Distribution and Trends in Alberta ___ 3

3.0 THREATS AND LIMITING FACTORS __ 5

3.1 Fluctuating Population Size 5

3.2 Habitat Destruction or Alteration 6

3.3 Oil and Gas Development 6

3.4 Agricultural Activities 7

3.5 Rural or Industrial Development 7

3.6 Military Land Use 7

3.7 Parasitism

3.8 Predation

3.9 Weather/Climate 8

$\underline{3.10 \text { Interactions and Cumulative Effects }}$ 8

4.0 RESEARCH NEEDS 8

Fluctuations in Population Size 9

Habitat Requirements, Use, and Management ___ 9

Weather and Climate

Diet

Effects of Landuse Activities ___ 9

$\begin{array}{ll}\text { Genetic Studies _ } & 10\end{array}$

5.0 LAND MANAGEMENT WITHIN THE SPECIES' RANGE ___ 10

6.0 RECOVERY STRATEGY 
6.1 Biological and Technical Feasibility of Recovery

6.2 Guiding Principles

6.3 Recovery Goal

6.4 Recovery Objectives

$\underline{6.5}$ Strategies for the Recovery of Ord's Kangaroo Rat in Alberta

Population Conservation and Management 13

Habitat Conservation and Management 14

Education and Information 14

Resource Acquisition 14

Research Needs 14

$\underline{\text { Plan Management and Administration }}$ 14

7.0 ACTION PLAN FOR RECOVERY 15

7.1 Population Conservation and Management 15

7.2 Habitat Conservation and Management 15

7.3 Education and Information 18

7.4 Resource Acquisition 18

7.5 Research Needs 18

7.6 Plan Management and Administration 19

8.0 TIMETABLE FOR IMPLEMENTATION AND SCHEDULE OF COSTS 20

9.0 SOCIO-ECONOMIC CONSIDERATIONS

11.0 LITERATURE CITED $ـ[22$

\begin{tabular}{ll}
12.0 APPENDIX 1 & 26 \\
\hline
\end{tabular}

\begin{tabular}{ll}
13.0 APPENDIX 2 & 27 \\
\hline
\end{tabular}

$\begin{array}{lr}14.0 \text { APPENDIX } 3 & 28 \\ & \end{array}$ 


\section{LIST OF FIGURES}

Figure 1. The distribution of Ord's kangaroo rats in Alberta according to population studies, museum specimens, and systematic distribution surveys.

\section{LIST OF APPENDICES}

Appendix 1. Prioritization of research needs for Ord's kangaroo rats in Alberta. 26

Appendix 2. Literature relevant to the status of Ord's kangaroo rats in Alberta and Canada. 27

Appendix 3. List of acronyms used. 28 


\section{ACKNOWLEDGEMENTS}

Elizabeth Podgurny (University of Calgary), Catherine Watson (EnCana Corporation Ltd.), and Major F. Martins (Canadian Forces Base Suffield) provided technical information to the team during the preparation of this plan.

Funding for the development of this recovery plan was provided by all of the member organizations on the Ord's Kangaroo Rat Recovery Team and by the Species at Risk program of Alberta Sustainable Resource Development. In addition, all specific conservation actions and research items proposed for 2004-2005 were successfully implemented on schedule, because of financial contributions (direct and indirect, e.g., in-kind) by:

- Alberta Conservation Association;

- Alberta Sport, Recreation, Parks and Wildlife Foundation;

- Alberta Sustainable Resource Development;

- Canadian Forces Base Suffield;

- EnCana Corporation Ltd.;

- Royal Alberta Museum;

- University of Calgary. 


\section{EXECUTIVE SUMMARY}

The Ord's kangaroo rat (Dipodomys ordii) is a small, nocturnal rodent that is highly adapted to survival in arid environments. Kangaroo rats spend the majority of their time in underground burrows that they construct in loose sandy soil. Individuals are active aboveground at night to search for food and mates. Kangaroo rats eat primarily plant seeds and stems that they collect in their external fur-lined cheek pouches and carry back to their burrows for eating and storage.

In May 2002, Ord's kangaroo rat was listed as Endangered under the Wildlife Act in Alberta. This designation was based on the Alberta population of Ord's kangaroo rats exhibiting a small breeding population ( $<1000$ adults in early spring) and dramatic within-year fluctuations in population size. In addition, the Alberta population of Ord's kangaroo rat is geographically isolated from other kangaroo rat populations and is limited to restricted habitat within the province. Nationally, the Ord's kangaroo rat was listed as a species of Special Concern in 1995 because of its localized distribution in Canada and its highly specific habitat requirements.

The goal of this recovery plan is to ensure a viable, naturally self-sustaining population of Ord's kangaroo rats in Alberta such that this species is no longer at risk of extinction in the province. Strategies for the recovery of kangaroo rats in Alberta focus on (1) minimizing any negative effects of human land uses on population size and fluctuations and (2) conserving and, where necessary, enhancing the net quantity and quality of habitat for this species in Alberta. More specifically, recovery strategies address: 1) population conservation and management, including monitoring of annual distribution and abundance; 2) habitat conservation and management, including monitoring and protecting important habitat and mitigating impacts of human activities on this habitat; 3 ) educational outreach to highlight the importance of the species and its ecological and habitat requirements; 4) resource acquisition to help fund implementation of the recovery initiatives; and 5) research to determine the best means of achieving long-term conservation of kangaroo rats in the province. 


\subsection{INTRODUCTION}

\subsection{Provincial and National Status}

In May 2002, the Ord's kangaroo rat (Dipodomys ordii) was listed as Endangered in Alberta, under the provincial Wildlife Act. This designation was based on the Alberta population of Ord's kangaroo rats exhibiting a small breeding population $(<1000$ adults in early spring $)$ and dramatic within-year fluctuations in population size. In addition, the Alberta population of Ord's kangaroo rats is geographically isolated from other kangaroo rat populations and is limited to restricted habitat within the province. The Initial Conservation Action Statement put forth by the Endangered Species Conservation Committee (ESCC), and approved by the Minister of Sustainable Resource Development, specified that a recovery plan should be developed within one year after designation to set goals, objectives, strategies, and management actions necessary to guide recovery efforts for Ord's kangaroo rats during the next five years. The action statement recommended that management should focus on conservation of existing populations by preventing habitat decline and by maintaining or restoring open sand habitat within the current range of the species. The ESCC also recommended that, pending the development and implementation of the recovery plan, policy regulations and management actions necessary to protect dens should be implemented. Nationally, the Ord's kangaroo rat was listed as a species of Special Concern in 1995 due to its localized occurrence in Alberta and Saskatchewan and because of its highly specific habitat requirements (Gummer 1995, COSEWIC 2003). The national status of this species is scheduled to be reassessed in 2006 .

\subsection{Recovery Team}

At the direction of the Minister of Sustainable Resource Development, the Alberta Ord's Kangaroo Rat Recovery Team was initiated in 2003 by the Director of Wildlife Management. The recovery team's primary responsibility is to facilitate and coordinate the conservation and recovery of this species in Alberta. It provides expert advice to the Minister on all matters relating to the management of Ord's kangaroo rats in Alberta. The team is also responsible for writing, updating, and guiding the implementation of the provincial recovery plan. The recovery team does not normally implement recovery actions directly, although team members and the organizations they represent will participate in implementing recovery actions identified in the recovery plan. The team will encourage and facilitate the involvement of all interested parties in the recovery of Ord's kangaroo rats in Alberta, whenever possible, and will report annually on progress of implementing recovery actions.

Membership of the recovery team includes representatives of parties likely to affect or to be affected by recovery actions: Fish and Wildlife Division (Alberta Sustainable Resource Development); Canadian Forces Base Suffield (Department of National Defence); Canadian Wildlife Service (Environment Canada); Royal Alberta Museum (Alberta Community Development); Prairie Farm Rehabilitation Administration (Agriculture and Agri-Food Canada); Special Areas Board; and a representative from each of the oil and gas industry, the ranching community, and the scientific community (University of Calgary). 


\subsection{SPECIES' BIOLOGY}

\subsection{Life History and Adaptations}

Ord's kangaroo rats are small (mean body mass $=59 \mathrm{~g}$, total body length $=230$ to $260 \mathrm{~mm}$ ), nocturnal rodents that are highly adapted for survival in arid environments (Gummer 1997a). They are identified by their orange-brown dorsal pelage, white ventral fur, large eyes, five-toed feet, and extremely long tails (tail length 140 to $160 \mathrm{~mm}$ ) (Garrison and Best 1990). Kangaroo rats are named for their bipedal, hopping-style of locomotion for which they have large hind limbs and feet. Despite their name, they are not closely related to Norway rats (Williams et al. 1993).

Kangaroo rats spend the majority of their time in underground burrows that they construct in loose sandy soil. Individuals emerge only at night to search for food and mates (Jorgensen and Hayward 1965, Kenagy 1973, O'Farrell 1974, Kaufman and Kaufman 1982, Gummer 1997a,b). Kangaroo rats eat primarily plant seeds and stems that they collect in their external fur-lined cheek pouches and carry back to their burrows for eating and storage (Lemen 1978, Johnson and Jorgensen 1981, Best and Hoditschek 1986). Kangaroo rats can live almost independent of drinking water, and exhibit many physiological and behavioural adaptations to conserve water (Fairbanks et al. 1983, French 1993).

Desert rodents, in particular kangaroo rats, tend to be relatively long-lived (2-6 years, Jones 1993) and slow to reproduce compared to other mammals of comparable body size (Stearns and Crandall 1981, Kenagy and Bartholomew 1985, Brown and Harney 1993). These characteristics are thought to be necessary due to the unpredictable nature of precipitation and food availability in desert environments. However, this pattern does not appear to apply to Ord's kangaroo rats in Alberta, which are short-lived and have high reproductive rates. In Alberta, individuals typically survive for less than one year, such that approximately $90 \%$ of the kangaroo rat population commonly dies over the course of one year, with the majority appearing to die of starvation or hypothermia overwinter (Gummer 1997a). However, from April through August, females may produce several litters and juveniles become sexually mature at approximately 47 to 60 days of age (Gummer 1997a). Therefore, young of the year often become sexually mature, breed, and produce one or more litters during their first year. High reproductive potential of the northernmost populations of kangaroo rats may be an adaptation that increases the odds of some offspring surviving the harsh winter conditions (Gummer1997a).

In Alberta, kangaroo rats typically spend the winter in their burrows where they hibernate and often arouse to feed on their underground food caches (Gummer 1997a,b, Gummer and Robertson 2003b). Hibernation during winter is thought to be a trait that is unique to Canadian populations (Gummer 1997a,b). Kangaroo rats from more southern populations (USA, Mexico) are not known to hibernate during the winter (French 1993, Gummer 1997a,b). 


\section{$\underline{2.2 \text { Habitat }}$}

\section{Natural Habitats}

Kangaroo rats require habitat that provides open, sparsely vegetated, sandy surfaces to facilitate their bipedal locomotion and excavation of extensive burrows and tunnels. Consequently, they are restricted to active sand dunes, arid grassland, and open scrubland with loose sandy soil and sparse vegetation. These features comprise a relatively small proportion of the landscape of southern Alberta, which probably accounts for the limited distribution and occurrence of this species in the province (Gummer 1995, 1997b).

\section{Anthropogenic Habitats}

Kangaroo rats also tend to be common in anthropogenic (human-created) habitats that are sparsely vegetated, including fireguards and roads with sandy banks, and in intensely grazed pastures and fallow fields in close proximity to sand hills (Smith and Hampson 1969, Gummer $1995,1997 a, b, 1999)$. It is possible that populations in these anthropogenic habitats are not as viable as those in more natural habitats (Gummer 1995, 1999). Anthropogenic habitats may represent population "sinks" whereby kangaroo rats using these features suffer higher mortality or reduced recruitment compared to kangaroo rats in natural habitats (Gummer and Robertson 2003a).

\section{Essential Habitat}

Although the general habitat associations of kangaroo rats are known, the specific habitat requirements of the species are not. Further research will be required to investigate how kangaroo rats select habitat and how they disperse through it, in order to be able to identify essential habitat for the species. In general, essential habitat is defined as the habitat that is necessary for the survival or recovery of the Ord's kangaroo rat.

\section{$\underline{2.3 \text { Population Distribution and Trends in Alberta }}$}

In Canada, Ord's kangaroo rats occur only in the sand hills of southeastern Alberta and southwestern Saskatchewan. In Alberta, kangaroo rats occur in the eastern portion of Canadian Forces Base Suffield (CFB Suffield) and adjacent areas between the South Saskatchewan and Red Deer Rivers near the villages of Bindloss and Empress (Figure 1). The known distribution of kangaroo rats in Alberta is approximately 2265 kilometers-squared (D. Gummer and D. Bender, pers. comm.). Approximately 36\% (811 kilometers-squared) of the Alberta range of kangaroo rats occurs within CFB Suffield. Of that 811 kilometers-squared within CFB Suffield, the Suffield National Wildlife Area (SNWA) contains 376 kilometers-squared of the species range in the province. The SNWA contains a high density of habitat, and therefore accounts for a disproportionately high number of kangaroo rats (estimated more than one-half of the Alberta population; D. Gummer and D. Bender, pers. comm.). Outside CFB Suffield, kangaroo rats were recently discovered at a site on the south side of the South Saskatchewan River, north of Hilda (Gummer and Robertson 2003a).

The Alberta population of kangaroo rats is geographically isolated from the nearest southern (Montana) populations by at least $350 \mathrm{~km}$ (Gummer 1997a,b). This isolation may have occurred as much as 5000 years ago (David 1971, Kenny 1989). The majority of the Alberta population is 
probably isolated to some degree from the Saskatchewan population, with the exception of the recently discovered population north of Hilda that is within $2 \mathrm{~km}$ of the Alberta-Saskatchewan border (Gummer and Robertson 2003a).

Determining population size and trend for this species are difficult because of the fluctuating nature of the kangaroo rat population in Alberta. Within-year fluctuations in population size commonly exceed one order of magnitude. In a 1995 survey, the Alberta population of kangaroo rats was estimated at 2200 to 4200 individuals of both sexes and all ages (Gummer 1997b). However, considering only mature individuals, the Alberta population at its minimum size is certainly well below 1000 individuals and may drop below 300 individuals (Gummer 1997b, Alberta Environment 2000). High birth and death rates typical of the Alberta population contribute to these fluctuations, and may be exacerbated by anthropogenic factors. At its lowest level, the kangaroo rat population in Alberta is at high risk of extinction from unpredictable natural events or anthropogenic factors. Because of the efficiency of surveying some anthropogenic habitats (e.g., linear features such as roads), greater numbers of kangaroo rats have been studied in anthropogenic habitats, as compared to natural habitats. Additional studies of population dynamics, emphasizing natural habitat types, are needed to determine the relative importance to, and roles of, natural and anthropogenic habitats in the overall survival of Ord's kangaroo rats in Alberta.

The dynamics of this population are best described by metapopulation dynamics. A metapopulation is characterized as a collection of local populations residing in spatially isolated patches of habitat that are subject to low levels of inter-patch dispersal or high rates of local extinction and re-colonization, termed patch turnover (Hanski and Gilpin 1991, Hanski 1998). The Alberta population of Ord's kangaroo rat functions as a metapopulation because of the highly dispersed and patchy nature of its habitat (particularly the natural habitats) and because patch turnover rates are exceptionally high. Of special concern to the conservation and management of the species in Alberta is the fact that metapopulations are not expected to occupy all of their habitat patches at any given time, even though some unoccupied patches may be of extremely high quality. Rather, individual patches of habitat are expected to undergo repeated patterns of occupancy, local extinction, and colonization (re-occupancy). Research by Bascompte and Solé (1996) has demonstrated that the loss of currently unoccupied habitat patches in a metapopulation can greatly reduce the probability of long-term population persistence. Hanski (1998) states that: "Managers should absorb the key message of classic metapopulation dynamics: currently unoccupied habitat fragments may be critical for long-term persistence."

Another key consideration for the maintenance of metapopulation structure is the degree of isolation between patches of suitable habitat. At the local scale, Hanski (1998) recommends that individual habitat patches (e.g., dunes) should be close enough to permit inter-patch dispersal and recolonization, but retain some degree of isolation to reduce the impact of regional-scale disturbance or ecological impacts (e.g., fire, spread of disease or parasites). At the broader, geographic scale, population isolation is often considered to have the opposite impact: isolation can lead to deleterious effects, such as genetic bottlenecks, inbreeding depression, or increasing population fluctuations caused by to localized disturbance. 




Figure 1. The distribution (dashed line) of Ord's kangaroo rats in Alberta according to population studies, museum specimens, and systematic distribution surveys (Gummer and Robertson 2003a).

\subsection{THREATS AND LIMITING FACTORS}

A variety of factors may threaten the Alberta population of kangaroo rats and its habitat. These factors may act independently, may interact, or may act simultaneously. The impact of interactions among factors and the cumulative effects of a number of factors may be difficult to identify and mitigate, but probably represent the largest threat to the population.

\section{$\underline{3.1 \text { Fluctuating Population Size }}$}

Seasonal fluctuations in population size can reduce the Alberta population to a few hundred individuals each year (Gummer 1997a,b; Alberta Environment 2000). Extremely small populations are particularly vulnerable to extirpation as a consequence of unpredictable natural disturbances or anthropogenic activities. Individuals from small populations may also have fewer mating opportunities that can lead to a reduction in lifetime reproductive success, a reduction in annual recruitment, or result in individuals mating with related individuals (potential inbreeding effects). 


\subsection{Habitat Destruction or Alteration}

The distribution of kangaroo rats in Alberta appears to be limited by the occurrence and distribution of preferred habitat: actively eroding sand dune complexes. Open sand dune habitat is becoming increasingly rare, fragmented, and altered in Alberta, apparently from a combination of gradual climatic changes and human-imposed landscape changes (Epp and Townley-Smith 1980, Gummer 1997b). Currently, several other species that have strong associations with sand hills are on provincial or federal species at risk lists or are being considered for protection, including small-flowered sand verbena (Tripterocalyx micranthus), western spiderwort (Tradescantia occidentalis), olive-backed pocket mouse (Perognathus fasciatus), and the hognose snake (Heterodon nasicus). Consequently, efforts to conserve and enhance sand dune habitats should benefit a diversity of species at risk in Alberta.

One potential threat to sand dune habitat is the stabilization of dunes by encroaching vegetation. Active sand dunes are maintained through a combination of climatic effects (e.g., wind), grazing, and fire. Traditionally, grazing by bison (Bison bison), elk (Cervus elaphus) and horses presumably played a role in maintaining active sand dunes. Elk were re-introduced to CFB Suffield in 1997 and 1998 to re-establish a large grazer on that prairie landscape. Shrub removals and controlled burns have been used elsewhere in North America to control encroachment of vegetation on open sand. Removal of shrubs was used successfully to increase population densities of Stephen's kangaroo rat (D. stephensi), an endangered species in California (Price et al. 1994a).

Another potential threat to sand dune habitat is the practice of discouraging erosion along roadways and agricultural land (Gummer 1997b). One common method used to limit erosion has been the placement of straw bales over eroding sand to encourage colonization by vegetative cover (Kenny 1989, Gummer 1995). As of 1992, the oil and gas industry terminated the practice of using flax bales to prevent erosion during development in the portion of the Middle Sand Hills that lies in CFB Suffield (D. Davies, pers. comm.).

Kangaroo rats opportunistically inhabit human-created, linear features, such as sandy trails, fireguards, and gravel roads in sand hill areas (Reynolds 1958, Stangl et al. 1992, Price et al. 1994b, Gummer 1995, 1997a,b Gummer et al. 1997, Gummer and Robertson 2003a). The consequences of occupying these alternative human-created habitats are not known. However, factors such as traffic mortality and cultivation of roadsides may decrease the suitability of these habitats for kangaroo rats.

\section{$\underline{3.3 \text { Oil and Gas Development }}$}

Oil and gas development is continuing to increase within the range of kangaroo rats. The effects of oil and gas development on the Alberta population of kangaroo rats are not fully understood. A recent study found no direct, immediate negative effects on survival of kangaroo rats of pipeline construction that employed special mitigation measures (Gummer and Robertson 2003b). However, unusually warm winter weather conditions during the study may have contributed to the high apparent success of mitigation. The study did reveal several indirect effects of pipeline construction activities that could potentially reduce kangaroo rat survival, 
including reduced home range sizes and reduced use of torpor during winter (Gummer and Robertson 2003b).

The effects of different types of industrial development activities, such as the development of permanent structures (e.g., wells), artificial night-time illumination of worksites, seismic surveys, and the consequences of variable timing of industrial activities, all remain to be investigated.

\section{$\underline{3.4 \text { Agricultural Activities }}$}

Kangaroo rats have been observed to colonize temporary fallow fields (Gummer and Robertson 2003a). However, the ephemeral nature of this habitat may not allow populations to be sustained in this particular habitat type (Gummer and Robertson 2003a). Kangaroo rats may migrate to such areas when populations are large or conditions favourable, but may abandon such areas or suffer unsustainably high mortality when those fields are cultivated in subsequent years.

Kangaroo rat populations have persisted under domestic grazing regimes for many years. Generally, moderate regimes of domestic grazing are not expected to pose a major threat to kangaroo rat populations. Over the long-term, periodic, intense grazing in some areas may serve to increase the amount of open sand, by reducing the amount of vegetation encroaching on sand dune habitat. However, domestic cattle that graze on the edges of open sand dune habitat could trample burrow complexes and individual rats.

\subsection{Rural or Industrial Development}

The impacts of rural or industrial developments on kangaroo rat populations are not well understood. Site development could impact kangaroo rats through a direct loss of habitat and direct mortality of individual animals. Kangaroo rats are known to be less active during periods of bright moonlight when predators may be more likely to detect them (Kaufman and Kaufman 1982, Gummer 1995, 1997b). Lighting or noise disturbances from rural or industrial developments may reduce the suitability of habitat for kangaroo rats, as well as increase the vulnerability of resident kangaroo rats to predation.

\section{$\underline{\text { 3.6 Military Land Use }}$}

A large proportion of the Alberta kangaroo rat population occurs in the SNWA within the boundaries of CFB Suffield. Active military exercises do not occur within the SNWA, and thus, are not expected to have a large impact on the population there. However, the potential impacts on kangaroo rats of military activities (e.g., proximity to visual, auditory, and olfactory disturbances, or habitat alteration from military training exercises) that occur in areas adjacent to the SNWA are not known.

\section{$\underline{\text { 3.7 Parasitism }}$}

Kangaroo rats are parasitized by many species of mites, ticks, chiggers, lice and fleas (reviewed by Whitaker et al. 1993). In addition, botflies (Cuterebra polita) infest approximately one-third of kangaroo rats in Alberta, but are not known to parasitize kangaroo rats elsewhere in their 
North American range (Gummer et al. 1997). Botfly parasitism has been found to be associated with decreased survival, reproduction, and growth in Townsend's voles (Microtus townsendii) (Boonstra et al. 1980); similar effects are possible with botfly parasitism of kangaroo rats.

\section{$\underline{3.8 \text { Predation }}$}

Predation on kangaroo rats by burrowing owls (Athene cunicularia), great-horned owls (Bubo virginianus), rattlesnakes (Crotalus viridis), and domestic cats has been observed (Gummer 1995, Gummer and Robertson 2003b, D. Gummer, pers. comm.). Other likely predators include long-eared owls (Asio otus), short-eared owls (A. flammeus), snowy owls (Nyctea scandiaca), bullsnakes (Pituophis catenifer), badgers (Taxidea taxus), bobcats (Felis rufus), coyotes (Canis latrans), least weasels (Mustela nivalis), long-tailed weasels (M. frenata), red foxes (Vulpes vulpes) and swift foxes (V. velox) (Gummer 1997b).

\subsection{Weather/Climate}

The existence of the Alberta population of kangaroo rats (at relatively high latitudes) requires that individuals experience long, cold winters, sometimes with continuous snow cover.

Kangaroo rats are not known to forage above-ground during cold temperatures $\left(\leq 11{ }^{\circ} \mathrm{C}\right)$ or during periods of continuous snow cover, which prevents opportunities to augment food stores or increase fat reserves (O'Farrell 1974, Gummer 1997a). Overwinter survival is low (e.g., 10\% of the population); the majority of individuals presumably die of starvation and hypothermia (Gummer 1997a).

Climate can also impact the persistence of kangaroo rats in Alberta, as it influences the amount and distribution of habitat available for kangaroo rats through its affect on erosion of sand dunes. Climate also affects the availability of food (i.e., seed crops) or vegetative cover used by kangaroo rats.

\section{$\underline{3.10 \text { Interactions and Cumulative Effects }}$}

In addition to the independent effects of limiting factors (detailed above), multiple limiting factors may interact to reduce the survival of kangaroo rats and contribute to the extreme fluctuations in population size that are characteristic of the Alberta population. For example, survival rates may be influenced by habitat type, because kangaroo rats in anthropogenic habitats may suffer higher rates of predation and higher levels of parasitism, and experience harsher winter micro-climates than kangaroo rats living in more natural habitats (Gummer 1999). Perhaps the greatest threat to the Alberta kangaroo rat population is the cumulative negative impact of several independent and/or interactive effects acting simultaneously on the population.

\subsection{RESEARCH NEEDS}

Several areas of research would provide information necessary to more effectively conserve and manage the Alberta population of kangaroo rats (Appendix 1). 
One of the criteria for listing Ord's kangaroo rats as Endangered is the tendency of the Alberta population to undergo dramatic, seasonal fluctuations in population size. These fluctuations can reduce the Alberta kangaroo rat population to a few hundred individuals in early spring.

Although fluctuations are partially caused by natural factors (e.g., high birth rates, high seasonal mortality), anthropogenic factors likely contribute to them, also. Research is needed on the factors contributing to fluctuations in population size and on the relative contribution of natural and anthropogenic factors to these fluctuations. Of particular interest is whether the use of anthropogenic habitats exacerbates fluctuations. It is possible that kangaroo rats living in anthropogenic habitats have higher rates of predation and parasitism, experience harsher winter microclimates, and may be subject to a nutritionally poor diet dominated by alien plant species such as Russian thistle (Salsola iberica). Research to investigate differences in abundance and survival between habitats is necessary to determine whether anthropogenic habitats create population "sinks". It is also crucial to investigate how interactions among limiting factors and the cumulative effects of these interacting factors influence population dynamics, because these effects may have a greater impact on the population than the independent effects of individual limiting factors.

\section{Habitat Requirements, Use, and Management}

Research is needed to establish the specific habitat requirements of kangaroo rats and how they select habitat and disperse through it. This information is needed to help define essential habitat for this species. Research is also required to understand long-term patterns of anthropogenic landscape change, and the factors influencing such. This will help explain current patterns of distribution and provide information to mitigate effects of landuse activities. Such information should also help elucidate the importance of habitat connectivity in the colonization or extinction of local populations of kangaroo rats. Experimental tests of small-scale translocations of kangaroo rats to previously occupied dunes or isolated dunes, and of re-activation of stabilized sand dunes will determine their usefulness as tools for conserving the species and its habitat.

\section{Weather and Climate}

Research is needed to determine the types and ranges of effects of weather and climate on Alberta kangaroo rats. Over the short term, harsh winter weather conditions are likely to influence survival of kangaroo rats. Natural and anthropogenic habitats may experience differences in the severity of winter weather conditions, leading to differential survival of kangaroo rats. Over the long term, climate and weather will affect the distribution and abundance of sand dune habitat across the landscape.

\section{$\underline{\text { Diet }}$}

Research is needed to understand the diet and selectivity of kangaroo rats to determine whether diets differ in natural and anthropogenic habitats. This information will also establish the importance of maintaining particular vegetation communities and will help focus reclamation efforts (e.g., seed mixes) carried out in kangaroo rat habitat.

\section{Effects of Landuse Activities}

Research is required to increase understanding of the effects of oil and gas developments, military land use, and agricultural, rural and industrial developments on kangaroo rats. These 
studies should elucidate mitigation strategies for these activities, including appropriate locations, timing, and reclamation activities.

\section{Genetic Studies}

Genetic studies are needed to elucidate several aspects of population dynamics that are relevant to the species' status and conservation in Alberta. Investigation of the genetic relatedness among local populations will help elucidate the reasons for frequent local population extinctions (e.g., inbreeding effects) and will provide a better understanding of the dynamics of the population (e.g., dispersal). Research to establish the origin of the recently discovered north-Hilda population on the south side of the South Saskatchewan River, and its relationship to populations on the north side of the river may provide insight into the population's role in connecting the adjoining ones. Research is also needed to establish the genetic relationship between the Alberta population and the population of Ord's kangaroo rats in Saskatchewan. Finally, research is needed to establish the taxonomic identity of the Alberta population, compared to populations in the United States. Given the long separation of the Canadian and U.S. populations and the unique adaptations of the Canadian population (e.g., hibernation), it is possible that the Canadian population could be classified as a new subspecies or species. This information is also important to establish whether kangaroo rats from U.S. populations could conceivably be used for translocations to Alberta (and Canada).

\subsection{LAND MANAGEMENT WITHIN THE SPECIES' RANGE}

Approximately one-third of the Alberta range of Ord's kangaroo rats and perhaps as much as two-thirds of the provincial population occur within the boundaries of CFB Suffield. As manager of this area, the Department of National Defence (DND) is committed to conducting military activities in an environmentally responsible and sustainable manner, as outlined in the (2003) DND Sustainable Defence Strategy. Advice on wildlife management on the Base is primarily provided by the Canadian Wildlife Service (CWS).

The majority of kangaroo rats on the Base occur in the SNWA. Since 1971, this area has been recognized as environmentally sensitive by DND and has been exempt from military activities. The formal designation of the National Wildlife Area within CFB Suffield (June 2003) was an important milestone for the conservation of Ord's kangaroo rats in Alberta: Some of the factors that may limit this species will be mitigated through the continuing regulation of human activities in the SWNA. This designation was made possible through the cooperation of the principle stakeholders: DND, CFB Suffield, CWS, EnCana Corporation Ltd., and the Prairie Farm Rehabilitation Administration (PFRA). The ongoing contributions of the SNWA to the Ord's kangaroo rat (and other species) is largely reliant on stakeholders' commitments to uphold current policies on regulation of human activities and mitigation protocols within the SNWA, and thus maintain the integrity of the SNWA for wildlife. This commitment has been reinforced by legislation under the Canada Wildlife Act.

Agricultural activity on the Base is restricted to medium-to-low intensity grazing by cattle, in the northwestern and southeastern portion of the Base (including portions of the SNWA). Currently, approximately 5000 cattle are pastured annually from June to October. Grazing activity is 
managed on a day to day basis by PFRA and is overseen by the Suffield Grazing Advisory Committee (SGAC), an independent committee of range management and wildlife professionals that makes recommendations to the Base Commander on stocking rates and environmental concerns. Grazing rates may be adjusted annually according to range conditions and to recommendations by SGAC. Because of multiple landuse considerations, grazing rates are typically lower than those on comparable lands outside the Base.

SGAC was instrumental in the removal of 1200 feral horses from the Base in 1994, due to concern for the environmental impact the horses were having on riparian areas, particularly in the Middle Sand Hills (D. Davies pers. comm., Weerstra and Wilkinson 1993). To re-establish a large native grazer on the landscape, elk were subsequently re-introduced $(1997,1998)$. Elk had been extirpated from the Suffield area in 1969. A recent census (February 2004) determined that approximately 850 elk reside on the Base (B. Smith pers. comm).

Since 1975, oil and gas reserves have been heavily developed on the Base, both inside and outside the SNWA. All sales of mineral rights on and off the Base are conducted by Alberta Energy (AE). The development of those resources is regulated by the Alberta Energy and Utilities Board (EUB). On provincial lands, surface activities for industrial development are managed by the Alberta Public Lands and Forests Division. On the base, coordination of aboveground industrial activites are facilitated by Suffield Industry Range Control (SIRC), which communicates protocols for safety, access, and environmental management to the oil and gas industry, and assists with compliance monitoring. Eleven oil and gas companies currently have development easements on the Base. However, all development activities in the SNWA are conducted by EnCana Corporation Ltd. Industrial infrastructure includes a road network and compressor stations around the perimeter of the Base.

The Suffield Environmental Advisory Committee (SEAC) was established in 1975 to monitor industrial developments within Suffield and provides advice to the Base Commander on environmental and regulatory requirements related to industrial activities. SEAC has been instrumental in developing protocols for operations in the SNWA that act to mitigate effects of oil and gas activities on the environment. Several significant changes to industrial operating procedures include drilling only during periods of frozen ground conditions $(1997,1980)$, development of an operating plan in the environmentally sensitive Middle Sand Hills (1978), utilization of native seed mixes in reclamation and protocols for reclamation, and the use of low impact drilling (1993). Operating protocols are periodically reviewed and revised as new information and technology becomes available. Within the SNWA, environmental assessments are required for each lease site and pipeline right-of-way. A setback distance of $250 \mathrm{~m}$ from kangaroo rat burrows has been established for wells and pipeline rights-of-way. In future, development proposed within the SNWA will be subject to an environmental assessment under the terms of the Canadian Environmental Assessment Act.

Outside CFB Suffield, kangaroo rats occupy lands managed primarily by the Special Areas Board and by private landowners, with smaller areas managed by the province. The Special Areas Board manages land in Special Areas 2, 3 and 4, including lease or sale of land, management of industrial activities on leases, and the provision of municipal services (e.g., essential services, infrastructure). Within the range of kangaroo rats, land managed by the 
province is primarily under grazing disposition. Alberta Sustainable Resource Development provides general guidelines for management of agricultural and industrial activities on these lands (available online at http://www3.gov.ab.ca/srd/fw/landuse/index.html). Provincial guidelines for industrial development on public land recommend a setback distance of $50 \mathrm{~m}$ from kangaroo rat burrows for industrial activities requiring no surface disturbance (e.g., surveying), and $100 \mathrm{~m}$ setback distance for any activities requiring surface disturbance. Scobie and Faminow (2000) suggested that these guidelines should be increased to $250 \mathrm{~m}$, similar to federal guidelines. Recently, Gummer and Robertson (2003b) provided several recommendations for mitigating industrial activities conducted in kangaroo rat habitat including (i) night-time surveys to establish the exact locations of burrows of resident kangaroo rats; (ii) marking of known kangaroo rat burrows using visible markers and informing construction workers to avoid marked burrows; (iii) prohibiting truck or large vehicles in areas where kangaroo rats are known to occur; and (iv) prohibiting night-time construction activities and the use of artificial lighting where kangaroo rats are known to occur.

\subsection{RECOVERY STRATEGY}

\subsection{Biological and Technical Feasibility of Recovery}

There is good potential for recovery of the Alberta population of Ord's kangaroo rats. Granted, the natural characteristics of the population (e.g., limited distribution, small size, propensity to fluctuate, and occurrence at the northern edge of the species range) may be factors that limit the possibility of achieving general gains in total population size. Despite these circumstances, conservation actions that address the primary reasons that the species is endangered, through mitigation of anthropogenic effects on population fluctuations and habitat, should assist with recovery of the species in Alberta.

Protection of the SNWA as currently practiced by stakeholders including DND, CWS, EnCana, SIRC, SEAC, PFRA, and SGAC will remain paramount in the conservation of Ord's kangaroo rats in Alberta. Protection of this area is now reinforced by legislation under the Canada Wildlife Act. Current operating procedures can be improved, as new information comes available on how specific anthropogenic activities impact kangaroo rats. Kangaroo rats also occupy land managed by the Special Areas Board, by private landowners and by the province. Conservation of kangaroo rats in these areas will require cooperation and commitment by these stakeholders to ensure that land is managed in a manner that is conducive to the conservation of kangaroo rats, while minimizing impacts on land use activities.

\subsection{Guiding Principles}

The conservation and management of Ord's kangaroo rats in Alberta will be guided by the following principles:

- The conservation of Ord's kangaroo rats is important because they are an irreplaceable component of Alberta biodiversity. 
- Loss of habitat, particularly natural habitat, for Ord's kangaroo rats is unacceptable.

- A cooperative approach with land managers, landowners, industry and other agencies is essential to the success of this plan. This includes shared stewardship, compatible land use and local commitment to management initiatives.

- Landowners and lessees will not be unduly affected by the costs associated with maintaining or enhancing habitat for Ord's kangaroo rats.

- Management actions will use tools resulting in the greatest benefit to Ord's kangaroo rats and will be based on the best information available. Implementation will not be delayed because of lack of specific supporting information.

- Knowledge gaps will be identified in the recovery plan. Ensuing research will be used to guide or improve management of the species, in the future.

- To the fullest extent possible, recovery actions will focus on achievable initiatives and on those initiatives deemed most effective in conserving Ord's kangaroo rats in Alberta.

- Recovery actions will embrace an ecosystem (holistic) approach to management.

- The recovery process will be guided by the concept of adaptive management, whereby specific actions are implemented, evaluated, and improved upon on an iterative basis.

\subsection{Recovery Goal}

The goal of the recovery plan is to ensure a viable, naturally self-sustaining population of Ord's kangaroo rats in Alberta such that this species is no longer at risk of extinction in the province.

\subsection{Recovery Objectives}

The objectives necessary to achieve this goal are:

- Mitigate threats to the population.

- Protect essential habitat.

- Encourage and support stewardship activities that maintain or enhance the population and its habitat.

- Conduct research that guides conservation and recovery.

\subsection{Strategies for the Recovery of Ord's Kangaroo Rat in Alberta}

Once implemented, the following recommended recovery strategies should serve to guide the conservation of this species in Alberta over the next five years.

\section{Population Conservation and Management}

1. Monitor the kangaroo rat population in Alberta, including population size, distribution, and fluctuations.

2. Determine the relative contributions of anthropogenic and natural factors to population fluctuations.

3. Minimize anthropogenic influences that amplify fluctuations in population size.

4. Identify the circumstances under which population management activities (e.g., translocations) are necessary and choose areas for these activities, whenever possible, that will minimize impacts on landowners, lessees, or other stakeholders. 


\section{Habitat Conservation and Management}

1. Monitor quantity and quality of essential habitat to ensure both are maintained.

2. Support existing management activities and implement additional management activities that conserve or enhance habitat for kangaroo rats.

3. Assess cumulative effects of landuse activities on kangaroo rat habitat.

4. Ensure landholders and other stakeholders are recognized for participating in habitat stewardship activities.

5. Whenever/wherever necessary and feasible, enhance habitat for kangaroo rats using techniques that will minimize impacts on landowners, lessees or other stakeholders.

\section{Education and Information}

1. Promote the recovery plan to stakeholders and the public.

2. Increase public awareness of kangaroo rat conservation in Alberta.

3. Engage publics in conservation and recovery activities, including population monitoring and research.

\section{$\underline{\text { Resource Acquisition }}$}

1. Identify resources required to implement conservation and recovery actions.

2. Secure logistical, financial, and in-kind support to implement the recovery plan.

3. Ensure recognition of individuals and organizations that support implementation of recovery and conservation activities.

\section{Research Needs}

1. Identify essential habitat, and its key attributes, and develop appropriate protection measures.

2. Determine the relative value of anthropogenic habitats for the Ord's kangaroo rat, and develop habitat protection measures, as appropriate.

3. Secure funding for other key areas of study that will contribute to or facilitate the conservation of kangaroo rats (see Appendix 1), engage qualified researchers, and undertake those investigations.

4. Establish interdisciplinary relationships and collaboration among researchers.

5. Ensure results from research are provided to supporters and stakeholders.

6. Update research needs and priorities, as necessary.

7. Establish and maintain relationships with landholders to facilitate access and cooperation.

8. Ensure recognition for individuals and organizations that support research.

\section{Plan Management and Administration}

1. Monitor, evaluate and report on the effectiveness of conservation activities.

2. Ensure that recovery actions complement, where possible, the conservation of other provincially or federally listed species at risk. 


\subsection{ACTION PLAN FOR RECOVERY}

\subsection{Population Conservation and Management}

1. Species specialists from government agencies, non-government organizations or universities will develop a standardized protocol with a robust experimental design for monitoring abundance and distribution of kangaroo rats in Alberta. This protocol will ensure that kangaroo rats are monitored in both natural and anthropogenic habitats. The Recovery Team recommends that this initiative be undertaken in year 2 .

2. Following the standardized protocol, government agencies, non-government organizations, or universities will conduct annual surveys of distribution and abundance of Ord's kangaroo rats in Alberta. The Recovery Team recommends that this initiative be undertaken in years 2 to 5 .

3. Pending research on factors contributing to fluctuations in population size and on approaches to mitigate these factors, encourage landholders and other stakeholders to implement management activities to mitigate or minimize effects of anthropogenic activities that result in fluctuations in population size. The Recovery Team recommends that this initiative be undertaken in years 4 and 5 .

4. If research shows that experimental translocations can be used successfully to re-establish local populations of kangaroo rats, government agencies, non-government organizations, or universities will develop a standardized protocol for conducting translocations. The Recovery Team recommends research on translocations during years 3 and 4; if early results indicate effectiveness is possible, a standardized protocol for conducting translocations should be developed in year 3 , and refined in year 4 .

5. If research shows that experimental translocations can be used successfully to re-establish local populations of kangaroo rats, government agencies, non-government organizations, or universities will formally implement translocations of kangaroo rats to open sand dunes in key areas within their known range, following the established protocol. The Recovery Team recommends that, if effectiveness is indicated, translocations will be formally implemented as a population management tool in years 4 and 5 .

\section{$\underline{7.2 \text { Habitat Conservation and Management }}$}

1. Alberta Fish and Wildlife Division will make application/recommendations to Alberta Public Lands and Forests Division and to the Special Areas Board to put protective notations, consultative notations or other protective designations on all quarter sections on public land identified as essential habitat for kangaroo rats. The Recovery Team recommends that this initiative be undertaken in year 3 and be updated, as necessary.

2. The Recovery Team recommends that the excellent record of habitat stewardship and wildlife protection in the SNWA be perpetuated and encourages DND, CWS, SEAC, SIRC, 
EnCana, SGAC, PFRA, and other stakeholders to uphold, and refine as necessary, current policies and mitigation protocols for human land uses in the SNWA.

3. Government agencies, non-government organizations, or universities will develop a standardized protocol with a robust experimental design for monitoring habitat identified as essential for kangaroo rats to determine whether any change in quantity or quality has occurred. The Recovery Team recommends that this initiative be undertaken in year 2 .

4. Following the standardized protocol, government agencies, non-government organizations, or universities will monitor habitat identified as essential for kangaroo rats every two years to determine whether any change in quantity or quality has occurred.

5. Alberta Fish and Wildlife Division, Alberta Public Lands and Forests Division, Special Areas Board, DND, CWS, SEAC, SIRC, AE, EUB, EnCana, SGAC, PFRA, other resource or land managers, or species specialists will cooperate to develop beneficial management practices (BMPs) for maintaining active sand dune habitat within the range of Ord's kangaroo rat. The intent will be for these managers to encourage implementation of these BMP's by stakeholders. The Recovery Team recommends that BMPs be developed in year 2 and be implemented in subsequent years.

6. Alberta Fish and Wildlife Division, Alberta Public Lands and Forests Division, Special Areas Board, DND, CWS, SEAC, SIRC, AE, EUB, EnCana, other resource or land managers, or species specialists will cooperate to develop BMPs for oil and gas development within the range of Ord's kangaroo rat, including recommendations outlined in current studies (e.g., Scobie and Faminow 2000, Gummer and Robertson 2003b). The intent will be for these managers to encourage implementation of these BMPs by stakeholders. The Recovery Team recommends that BMPs be developed in year 2 and be implemented in subsequent years. In the interim, recommendations in the individual research documents will be used to mitigate impacts of oil and gas development on kangaroo rats and their habitat.

7. Alberta Fish and Wildlife Division, Alberta Public Lands and Forests Division, Special Areas Board, DND, CWS, SEAC, SIRC, AE, EUB, EnCana, SGAC, PFRA or other organizations will cooperate to develop access management plans within the range of Ord's kangaroo rat to mitigate new developments. The intent of these plans is to encourage multi-stakeholder use of existing roadways, thereby minimizing the construction of new roads and trails. The Recovery Team recommends that access management plans be developed in Year 2 and be implemented in subsequent years.

8. Alberta Fish and Wildlife Division, Alberta Public Lands and Forests Division, Special Areas Board, DND, CWS, SGAC, PFRA, other resource or land managers, or species specialists will cooperate to develop BMPs for agricultural activities within the range of Ord's kangaroo rat. The intent will be for these managers to encourage implementation of these BMPs by stakeholders. The Recovery Team recommends that BMPs be developed in year 2 and be implemented in subsequent years. 
9. Government agencies, non-government organizations, or other resource or land managers will develop operating procedures for planning residential developments within areas of essential habitats. These procedures will include a recommendation that environmental assessments and mitigation plans be developed for proposed rural developments. The Recovery Team recommends that this initiative be undertaken in year 2 .

10. Alberta Fish and Wildlife Division, Alberta Public Lands and Forests Division, Special Areas Board, DND, CWS, SEAC, SIRC, AE, EUB, EnCana, SGAC, PFRA, other resource or land managers, or species and habitat specialists will cooperate to develop BMP's to minimize cumulative negative effects of anthropogenic activities on kangaroo rats. The intent will be for these managers to encourage implementation of these BMP's by stakeholders. The Recovery Team recommends that BMP's be developed in year 2 and be implemented in subsequent years.

11. Alberta Fish and Wildlife Division in cooperation with other agencies (e.g., Special Areas Board, Alberta Public Lands and Forests Division) will contact private landowners and lessees within the range of current distribution for the Ord's kangaroo rat in Alberta, and provide information (pamphlets, etc.) on programs and incentives to maintain or restore native habitat (e.g., Green Cover program) and information on the biology and habitat requirements of kangaroo rats (e.g., fact sheets). Restoration activities conducted to complement recovery of kangaroo rats should include the establishment of a heterogeneous community of native cover interspersed with bare patches of sandy soil. The Recovery Team recommends that this initiative be undertaken in years 1 to 5 .

12. When necessary, government agencies or non-government conservation organizations will assist lessees and land managers to manage their land, through the provision of various improvements, in a manner that helps to conserve kangaroo rats. Such improvements might include fencing, water developments or provision of native seed mixes. The Recovery Team recommends that this initiative be undertaken in years 2 to 5 .

13. If research shows that experimental habitat restoration (reactivation) can be used successfully to increase the quality or quantity of habitat for kangaroo rats, then government agencies, non-government agencies, or universities will develop a standardized protocol for conducting habitat restoration. The protocol should include a review of the types of tools available for undertaking restoration activities and how, when, and where restoration activities should take place. The Recovery Team recommends that research on habitat restoration should begin in years 2 and 3 and, if effective, that a protocol be developed in year 3.

14. If research shows that experimental habitat restoration (reactivation) can be used successfully to increase the quality or quantity of habitat for kangaroo rats, then government agencies, non-government agencies, or universities will undertake habitat creation, including reactivation of stabilized dunes in CFB Suffield or other strategic areas where costs to landholders would be minimized. The Recovery Team perceives that habitat restoration could be formally implemented, potentially, as a management tool in years 4 and 5 . 
15. Landholders and other stakeholders participating in habitat stewardship activities will be acknowledged on printed materials, web sites, presentations and possibly special events pertaining to kangaroo rat conservation and recovery.

\section{$\underline{7.3 \text { Education and Information }}$}

1. Alberta Fish and Wildlife Division will make the recovery plan available to the public and interested stakeholders on the Alberta Species at Risk web site and in hard copy from the Alberta Sustainable Resource Development Information Centre, after it has received Ministerial approval.

2. Alberta Fish and Wildlife Division will update the current fact sheet on kangaroo rats, as required, to promote conservation of this species to the general public. This item will be made available to stakeholders and landholders within the range of the species. This fact sheet will encourage stakeholders and the public to provide observations of kangaroo rats to resource managers.

3. Government agencies or non-government organizations will develop a fact sheet on managing sand dune habitat in ways that maintain or enhance habitat for open sand dune obligates, including kangaroo rats. The Recovery Team recommends that this initiative be undertaken in year 3 .

4. Alberta Fish and Wildlife Division and other organizations [e.g., Royal Alberta Museum (RAM)] will undertake or encourage educational outreach on kangaroo rats, such as the development of displays or digital presentations to educate publics on kangaroo rats and their conservation requirements, and the importance of research in conservation and recovery. The Recovery Team recommends that this initiative be undertaken in years 2 to 5 .

5. Alberta Fish and Wildlife Division or other agencies (e.g., RAM) will develop a dynamic web site with information on kangaroo rats, including their biology, conservation and recovery efforts, and current research activities and results. The Recovery Team recommends that this initiative be undertaken in year 2 and be updated each year.

\subsection{Resource Acquisition}

1. Cooperating organizations and researchers will annually approach government agencies, nongovernment organizations, and industry to participate in or fund recovery initiatives.

2. Individuals and organizations supporting conservation and recovery actions will be acknowledged on printed materials, web sites, presentations, press releases and possibly other special events.

\subsection{Research Needs}

1. Government agencies with the assistance of non-government organizations, or universities will identify essential habitat for kangaroo rats and will develop habitat maps denoting 
essential habitat for kangaroo rats. These maps will be distributed to resource or land use managers (e.g., Alberta Fish and Wildlife Division, Alberta Public Lands and Forests Division, Special Areas Board, DND, CWS, SEAC, SIRC, AE, EUB, EnCana, SGAC, PFRA) and should be used as the basis for permitting and mitigating land use activities and sale or trade of public land. The Recovery Team recommends that this initiative be undertaken primarily in year 2 and be updated as necessary.

2. The Recovery Team has identified and prioritized several areas of research that will provide information necessary to help conserve and maintain kangaroo rats in Alberta. This research includes research on population fluctuations; habitat requirements, use and valuation (including anthropogenic habitats); diet; effects of weather, climate, and of land use activities on kangaroo rat populations and habitat; and genetics (See Research Needs and Appendix 1).

3. Alberta Fish and Wildlife Division, other agencies, and researchers, will ensure that data on kangaroo rats are entered into centralized databases [provincial Biodiversity/Species Observation Database (BSOD), Royal Alberta Museum (RAM), Special Areas Board] following each survey season. Alberta Fish and Wildlife Division will maintain a contact list for managers of these databases for referrals on data requests on this species.

4. The Co-chairs of the Recovery Team, in coordination with Alberta Fish and Wildlife Division (Southeast Region), DND, and researchers, will ensure that all research activities are coordinated each year in order to maximize benefits from research and to keep the recovery team informed of ongoing studies. Coordination of activities will include engaging qualified researchers in studies, ensuring adequate reporting of results, encouraging collaboration among researchers and ensuring that research priorities are updated, as necessary.

5. Individuals and organizations that support research on kangaroo rats will be recognized on printed materials, web sites, presentations, press releases and possibly other special events.

\subsection{Plan Management and Administration}

1. Alberta Fish and Wildlife Division will convene the Alberta Ord's Kangaroo Rat Recovery Team a minimum of once annually. At these meetings, the Recovery Team will review progress on implementation of the plan, will evaluate the effectiveness of recovery actions, and will develop new recovery actions, as required. The Co-chairs of the recovery team will provide an annual report to the Director of Wildlife Management detailing progress on implementation of the plan and any recommended changes to the action plan.

2. The Co-chairs of the Recovery Team will communicate with other recovery teams, particularly those for other species that rely on open, sandy habitats, to ensure that recovery actions for kangaroo rats complement, where possible, those for other provincially or federally listed species at risk. 


\subsection{TIMETABLE FOR IMPLEMENTATION AND SCHEDULE OF COSTS}

The following table provides a timeline for implementation of activities identified by the recovery team as being important to the conservation of kangaroo rats in Alberta, and the estimated minimum costs associated with their implementation. It is anticipated that a variety of agencies will participate in the funding and implementation of these activities. Estimated costs shown are direct and essential in-kind costs to implement the recovery actions. Costs associated with team members' expenses to attend recovery team meetings are not included in the table, but represent valued and necessary contributions associated with implementation of the recovery plan. Direct costs for research actions in 2004-2005 were largely met through the generosity of CFB Suffield, EnCana Corporation Ltd., and the Alberta Conservation Association.

\begin{tabular}{|c|c|c|c|c|c|c|c|c|}
\hline \multirow{2}{*}{$\begin{array}{l}\text { Recovery } \\
\text { Plan } \\
\text { Section } \\
\end{array}$} & \multirow[t]{2}{*}{ Action } & \multirow{2}{*}{$\begin{array}{c}\text { Lead } \\
\text { Agency }\end{array}$} & \multicolumn{5}{|c|}{ Cost (thousands/year) } & \multirow[t]{2}{*}{ Total } \\
\hline & & & 2004-05 & 2005-06 & 2006-07 & 2007-08 & 2008-09 & \\
\hline 7.1 & Population Management & & & & & & & \\
\hline \multirow{6}{*}{$\begin{array}{l}1 \\
2 \& \text { A1. } 1 \mathrm{abg} \\
3 \\
4 \\
5\end{array}$} & \multirow{6}{*}{$\begin{array}{l}\text { Popn Monitoring Protocol } \\
\text { Population Monitoring } \\
\text { Mitigation } \\
\text { Translocation protocol } \\
\text { Translocations }\end{array}$} & \multirow{6}{*}{$\begin{array}{l}\text { Researchers } \\
\text { Various } \\
\text { Various } \\
\text { Various } \\
\text { Various }\end{array}$} & \multirow{6}{*}{ * } & \multirow{5}{*}{$\begin{array}{l}10 \\
20\end{array}$} & \multirow{5}{*}{20} & \multirow{4}{*}{$\begin{array}{c}20 \\
5\end{array}$} & \multirow{4}{*}{$\begin{array}{c}20 \\
5\end{array}$} & 10 \\
\hline & & & & & & & & 80 \\
\hline & & & & & & & & 10 \\
\hline & & & & & & & & 5 \\
\hline & & & & & & 20 & 20 & 40 \\
\hline & & & & 30 & 25 & 45 & 45 & 145 \\
\hline 7.2 & Habitat Management & & & & & & & \\
\hline 3 & Habitat Monitor Protocols & Researchers & & 5 & & & & 5 \\
\hline 4 & Monitor Habitat & Various & * & & 15 & & 15 & 30 \\
\hline 5 & BMP sand dune habitat & Various & & 5 & & & & 5 \\
\hline 6 & BMP industrial & Various & & 5 & & & & 5 \\
\hline 7 & Access Mgt Plans & Various & & 10 & & & & 10 \\
\hline 8 & BMP agricultural & Various & & 5 & & & & 5 \\
\hline 9 & BMP Res/Indust Develop & Various & & 5 & & & & 5 \\
\hline 10 & BMP Cumulative & Various & & 5 & & & & 5 \\
\hline 12 & Habitat improvements & Various & & 10 & 10 & 10 & 10 & 40 \\
\hline 13 & Habitat restoration protocol & Various & & & 5 & & & 5 \\
\hline 14 & Habitat restoration & Various & & & & 10 & 10 & 20 \\
\hline \multirow[t]{2}{*}{15} & \multirow[t]{2}{*}{ Recognition of stewardship } & \multirow[t]{2}{*}{ Various } & 1 & 1 & 1 & 1 & 1 & 5 \\
\hline & & & 1 & 51 & 31 & 21 & 36 & 140 \\
\hline 7.3 & Education / Information & & & & & & & \\
\hline \multirow{5}{*}{$\begin{array}{l}1 \\
3 \\
4 \\
5\end{array}$} & \multirow{5}{*}{$\begin{array}{l}\text { Publish Plan } \\
\text { Sand dune fact sheet } \\
\text { Outreach } \\
\text { Web site Develop/Updates }\end{array}$} & \multirow{5}{*}{$\begin{array}{c}\text { FW } \\
\text { FW } \\
\text { Various } \\
\text { Various }\end{array}$} & \multirow[t]{4}{*}{1} & & & & & 1 \\
\hline & & & & & 5 & & & 5 \\
\hline & & & & 5 & 5 & 5 & 5 & 20 \\
\hline & & & & 3 & 1 & 1 & 1 & 6 \\
\hline & & & 1 & 8 & 11 & 6 & 6 & 32 \\
\hline 7.4 & Resource Acquisition & & & & & & & \\
\hline 1 & Funding Securement & Various & 2 & 2 & 2 & 2 & 2 & 10 \\
\hline 2 & Recognition of support & FW & 1 & 1 & 1 & 1 & 1 & 5 \\
\hline & & & 3 & 3 & 3 & 3 & 3 & 15 \\
\hline 7.5 \&App.1 & Research & & & & & & & \\
\hline $1 \& \mathrm{~A} 1.2$ & Essential Habitat \& Maps & Various & 5 & 35 & 15 & & 10 & 65 \\
\hline $2 \& \mathrm{~A} 1.1 \mathrm{bcd}$ & Anthropogenic effects & Researchers & 40 & 20 & & & & 60 \\
\hline $2 \& \mathrm{Al}$. lef & PF: Predation \& Parasitism & Researchers & 38 & 15 & & & & 53 \\
\hline $2 \& \mathrm{Al} .1 \mathrm{~h}$ & PF:interactions/cumulative & Researchers & 35 & 10 & & & & 45 \\
\hline $2 \& \mathrm{~A} 1.3$ & Weather/climate & Researchers & 10 & 10 & 5 & & & 25 \\
\hline $2 \& \mathrm{~A} 1.4$ & Landscape Change & Researchers & 10 & 15 & & & & 25 \\
\hline $2 \&$ A 1.5 & Translocate/reintroduce & Researchers & & & 30 & 20 & & 50 \\
\hline $2 \& \mathrm{~A} 1.6$ & Reactivate habitat & Researchers & & 10 & 10 & 5 & 5 & 30 \\
\hline $2 \& \mathrm{~A} 1.7$ & Diet & Researchers & 14 & 25 & & & & 39 \\
\hline $2 \& \mathrm{~A} 1.8$ & Oil and gas & Researchers & $*$ & $*$ & & 20 & 20 & $40^{*}$ \\
\hline $2 \&$ Al. 9 & Military land use & Researchers & * & $*$ & & & & $*$ \\
\hline $2 \&$ A 1.10 & Agriculture & Researchers & & & & 15 & 15 & 30 \\
\hline $2 \& \mathrm{~A} 1.11$ & Rural development & Researchers & & & & 15 & 15 & 30 \\
\hline $2 \& \mathrm{~A} 1.12$ & Hibernation patterns & Researchers & & & 20 & 30 & & 50 \\
\hline
\end{tabular}




\begin{tabular}{|c|c|c|c|c|c|c|c|c|}
\hline $\begin{array}{l}2 \& \mathrm{~A} 1.13-15 \\
2 \& \mathrm{~A} 1.16 \\
5\end{array}$ & $\begin{array}{l}\text { Genctic analysis } \\
\text { Taxonomic identity } \\
\text { Recognition of support }\end{array}$ & $\begin{array}{l}\text { Researchers } \\
\text { Rescarchers } \\
\text { Various }\end{array}$ & 1 & 1 & $\begin{array}{c}15 \\
20 \\
1\end{array}$ & 10 & 1 & $\begin{array}{c}25 \\
20 \\
5\end{array}$ \\
\hline & Recognition of support & & 153 & 141 & 116 & 116 & 66 & 592 \\
\hline 7.6 & Plan Management & & & & & & & \\
\hline \multirow[t]{3}{*}{1} & \multirow[t]{2}{*}{ Annual Mceting/Report } & \multirow[t]{2}{*}{ FW } & 1 & 1 & 1 & 1 & 1 & 5 \\
\hline & & & 1 & 1 & 1 & 1 & 1 & 5 \\
\hline & TOTAL & & 159 & 234 & 187 & 192 & 157 & 929 \\
\hline
\end{tabular}

* costs covered in other activities for this year. Note: Various indicates that a number of agencies were identified in the action plan as potential agencies to lead implementation. Please refer to text for more details. Population fluctuations (PF), Alberta Fish and Wildlife Division (FW). Funds for all proposed activities in year 1 were successfully raised by recovery team members, with a surplus to be used for completion of selected research activities in year 2 .

\subsection{SOCIO-ECONOMIC CONSIDERATIONS}

It is a guiding principle of the recovery plan that landowners and leaseholders should not be unduly affected by costs associated with maintaining and enhancing habitat for Ord's kangaroo rats. However, potential economic costs may include changes to grazing management that could involve decreased productivity or increased costs for livestock production. Potential costs associated with industrial development may include restrictions on resource extraction or increased costs for extraction or development resulting from mitigation measures. Habitat creation or reactivation may require tools, such as controlled burns, that pose some risk to stakeholders should they become uncontrolled. However, these tools will be implemented using established protocols and will be used in strategic areas to minimize risks to stakeholders.

A potential economic benefit for leaseholders and landowners is the opportunity to obtain range/habitat improvements that increase the quality and productivity of their rangelands. Best management practices for agricultural activities could also lead to increased productivity of rangelands.

Activities that lead to the maintenance of an intact prairie landscape allows for the persistence of Alberta's grazing heritage for future generations. Conservation of an intact prairie landscape may also increase biodiversity and ecotourism potential, and create additional recreational opportunities (e.g., hunting).

\subsection{PLAN REVIEW AND AMENDMENT}

The life of this plan is five years. The Alberta Ord's Kangaroo Rat Recovery Team will meet once annually to conduct an annual review of the plan, to monitor the implementation of the plan, and to determine effectiveness of recovery actions. A report on the results of these reviews will be submitted annually to the Director of Wildlife Management by the co-chairs. Recovery action plans are considered "living" documents and recovery actions can be amended during these reviews as new information becomes available, conditions change, or circumstances warrant. At the end of 5 years, the Recovery Team will meet again to determine whether any other amendments are required, prior to the plan being renewed for another five years. The Recovery Team may determine that the existing recovery plan is suitable or is in need of revision. 


\subsection{LITERATURE CITED}

Alberta Environment. 2000. First report of the Alberta Endangered Species Conservation Committee. Alberta Environment. Publication No. T/565. Edmonton, AB. 24 pp.

Bascompte, J. and R.V. Solé. 1996. Habitat fragmentation and extinction thresholds in spatially explicit models. Journal of Animal Ecology, 65: 465-473.

Best, T. L. and B. Hoditschek. 1986. Relationships between environmental variation and the reproductive biology of Ord's kangaroo rat (Dipodomys ordii). Mammalia 50: 173-183.

Boonstra, R., C. J. Krebs, and T. D. Beacham. 1980. Impact of botfly parasitism on Microtus townsendii populations. Canadian Journal of Zoology 58: 1683-1692.

Brown, J. H. and B. A. Harney. 1993. Population and community ecology of heteromyid rodents in temperate habitats. Pp. 618-651 in Biology of the Heteromyidae (Genoways, H. H. and J. H. Brown, eds.). American Society of Mammalogists, Special Publication No. 10. Provo, Utah. 719 pp.

COSEWIC. 2004. COSEWIC Assessment Results, May, 2004. Committee on the Status of Endangered Wildlife in Canada. Ottawa, ON. 44 pp.

David, P. P. 1971. The Brookdale road section and its significance in the chronological studies of dune activities in the Brandon Sand Hills of Manitoba. Pp. 293-299 in Geoscience Studies in Manitoba (Turnock, A. C., ed.). The Geological Society of Canada, Special Paper No. 9. Toronto, ON. 352 pp.

Department of National Defence. 2003. Environmentally Sustainable Defence Activities. Sustainable Defence Strategy 2003. www.forces.gc.ca/admie/dge/sds/sds2_e.htm

Epp, H. T. and L. Townley-Smith. 1980. The Great Sand Hills of Saskatchewan. Saskatchewan Department of the Environment, Regina, SK. 15 pp.

Fairbanks, W. S., D. Greegor, L. Staudinger, and E. Bitterbaum. 1983. Water conservation of the kangaroo rat, Dipodomys ordii. Transactions of the Nebraska Academy of Science 11: $27-30$.

French, A. R. 1993. Physiological ecology of the Heteromyidae: economics of energy and water utilization. Pp. 509-538 in Biology of the Heteromyidae (Genoways, H. H. and J. H. Brown, eds.). American Society of Mammalogists, Special Publication No. 10, Provo, Utah. 719 pp.

Garrison, T. E. and T. L. Best. 1990. Dipodomys ordii. American Society of Mammalogists, Mammalian Species No. 353, Provo, Utah. 10 pp. 
Gummer, D. L. 1995. Status report on the Ord's kangaroo rat (Dipodomys ordii) in Canada. Committee on the Status of Endangered Wildlife in Canada. Ottawa, ON. 27 pp.

Gummer, D. L. 1997a. Effects of latitude and long-term isolation on the ecology of northern Ord's kangaroo rats (Dipodomys ordii). MSc. thesis, University of Calgary. Calgary, AB. $111 \mathrm{pp}$.

Gummer, D. L. 1997b. Ord's kangaroo rat (Dipodomys ordii). Alberta Environment, Wildlife Management Division, Wildlife Status Report No. 4. Edmonton, AB. 16 pp.

Gummer, D. L. 1999. Distribution and abundance of Ord's kangaroo rats in Suffield National Wildlife Area. Prepared for the Canadian Wildlife Service, Edmonton, AB. 26 pp.

Gummer, D. L., M. R. Forbes, D. J. Bender, and R. M. R. Barclay. 1997. Botfly (Diptera: Oestridae) parasitism of Ord's kangaroo rats (Dipodomys ordii) at Suffield National Wildlife Area, Alberta, Canada. Journal of Parasitology 83: 601-604.

Gummer, D. L. and S. E. Robertson. 2003a. Distribution of Ord's kangaroo rats in southeastern Alberta. Alberta Sustainable Resource Development, Fish and Wildlife Division. Species at Risk Report No. 63. Edmonton, AB. 16 pp.

Gummer, D. L. and S. E. Robertson. 2003b. Evaluation of activities and survival of Ord's kangaroo rats during and post-construction of the North Suffield pipeline. Prepared for EnCana Suffield Gas Pipeline Inc. Provincial Museum of Alberta, Edmonton, AB. $43 \mathrm{pp}$.

Hanski, I. 1998. Metapopulation dynamics. Nature 396: 41-49.

Hanski, I. and M. Gilpin 1991. Metapopulation dynamics: Brief history and conceptual domain. Biological Journal of the Linnean Society 42: 3-16.

Jones, W. T. 1993. The social system of Heteromyid rodents. Pp. 575-595 in Biology of the Heteromyidae (Genoways, H. H. and J. H. Brown, eds.). American Society of Mammalogists, Special Publication No. 10. Provo, Utah. 719 pp.

Jorgensen, C. D. and C. L. Hayward. 1965. Mammals of the Nevada Test Site. Brigham Young University Science Bulletin (Biological Series) 6: 1-81.

Johnson, T. K. and C. D. Jorgensen. 1981. Ability of desert rodents to find buried seeds. Journal of Range Management 34: 312-314.

Kaufman, D. W. and G. A. Kaufman. 1982. Effect of moonlight on activity and microhabitat use by Ord's kangaroo rat (Dipodomys ordii). Journal of Mammalogy 63: 309-312.

Kenagy, G. J. 1973. Daily and seasonal patterns of activity and energetics in a Heteromyid rodent community. Ecology 54: 1201-1219. 
Kenagy, G. J. and G. A. Bartholomew. 1985. Seasonal reproductive patterns in five coexisting California desert rodent species. Ecological Monographs 55: 371-397.

Kenny, R. J. L. 1989. Population, distribution, habitat use, and natural history of Ord's kangaroo rat (Dipodomys ordii) in the sand hill areas of south-western Saskatchewan and south-eastern Alberta. M.Sc. thesis, University of Manitoba, Winnipeg, MB. 69 pp.

Lemen, C. 1978. Seed size selection in heteromyids: a second look. Oecologia 35: 13-19.

O'Farrell, M. J. 1974. Seasonal activity patterns of rodents in a sagebrush community. Journal of Mammology 55: 809-823.

Price, M. V., R. L. Goldingay, L. S. Szychowski, and N. M. Waser. 1994a. Managing habitat for the endangered Stephens' kangaroo rat (Dipodomys stephensi): effects of shrub removal. American Midland Naturalist 131: 9-16.

Price, M. V., P. A. Kelly, and R. L. Goldingay. 1994b. Distances moved by Stephens' kangaroo rat (Dipodomys stephensi Merriam) and implications for conservation. Journal of Mammalogy 75: 929-939.

Reynolds, H. G. 1958. The ecology of the Merriam Kangaroo Rat (Dipodomys merriami Mearns) on the grazing lands of southern Arizona. Ecological Monographs 28: 111-127.

Scobie, D. and C. Faminow. 2000. Development of standardized guidelines for petroleum industry activities that affect COSEWIC Prairie and Northern Region vertebrate species at risk. Report prepared for Environment Canada, Prairie and Northern Region, Edmonton, AB. 42 pp.

Smith, H. C. and M. J. Hampson. 1969. A kangaroo rat colony in Alberta. Blue Jay 27: 224225.

Stangl, F. B. Jr., T. S. Schafer, J. R. Goetze, and W. Pinchak. 1992. Opportunistic use of modified and disturbed habitat by the Texas Kangaroo Rat (Dipodomys elator). Texas Journal of Science 44: 25-35.

Stearns, S. C. and R. E. Crandall. 1981. Quantitative predictions of delayed maturity. Evolution 35: 455-463.

Weerstra, B.G. and K. E. Wilkinson. 1993. Range assessment of the Northeast Quadrant Canadian Forces Base Suffield. Report prepared for the Department of National Defence. Biota Consultants. 75 pp. + appendices and maps.

Whitaker, J. O. Jr., W. J. Wrenn, and R. E. Lewis. 1993. Parasites. Pp. 386-478 in Biology of the Heteromyidae (Genoways, H. H. and J. H. Brown, eds.). American Society of Mammalogists, Special Publication No. 10. Provo, Utah. 719 pp. 
Williams, D. F., H. H. Genoways, and J. K. Braun. 1993. Taxonomy and Systematics. Pp. 38196 in Biology of the Heteromyidae (Genoways, H. H. and J. H. Brown, eds.).

American Society of Mammalogists, Special Publication No. 10. Provo, Utah. 719 pp. 


\subsection{APPENDIX 1}

Prioritization of research needs for Ord's kangaroo rats in Alberta.

\begin{tabular}{|c|c|c|c|}
\hline Research Need & Importance $^{1}$ & Status $^{2}$ & Effort $^{3}$ \\
\hline \multicolumn{4}{|l|}{ 1. Population Fluctuations: } \\
\hline (a) Annual population and distribution monitoring & 1 & $\mathrm{X}$ & 1 \\
\hline (b) Causes and range of fluctuations & 1 & $\mathrm{X}$ & 2 \\
\hline (c) Consequences of occupying anthropogenic, linear habitats & 1 & $\mathrm{X}$ & 1 \\
\hline (d) Source-sink population dynamics & 1 & $X$ & 2 \\
\hline (e) Anthropogenic effects on botfly parasitism & 1 & $\mathrm{X}$ & 1 \\
\hline (f) Anthropogenic effects on predation & 1 & $\mathrm{X}$ & 2 \\
\hline $\begin{array}{l}\text { (g) Anthropogenic effects on overwinter survival (interactions with } \\
\text { severity of winter) }\end{array}$ & 1 & $\mathrm{X}$ & 2 \\
\hline $\begin{array}{l}\text { (h) Interactions between limiting factors and cumulative effects of } \\
\text { limiting factors }\end{array}$ & 1 & $\mathrm{X}$ & 2 \\
\hline $\begin{array}{l}\text { 2. Habitat characteristics, requirements, selection, including a review } \\
\text { and synthesis of current knowledge }\end{array}$ & 1 & $\mathrm{X}$ & 1 \\
\hline 3. Effects and role of weather and climate & 1 & & 2 \\
\hline $\begin{array}{l}\text { 4. Long-term patterns of anthropogenic landscape change and } \\
\text { correlations }\end{array}$ & 1 & & 2 \\
\hline $\begin{array}{l}\text { 5. Effectiveness of small-scale translocations/re-introductions to isolated } \\
\text { habitats }\end{array}$ & 1 & & 3 \\
\hline 6. Effectiveness of re-activation of stabilized sand dune habitats & 1 & & 3 \\
\hline 7. Diet composition and selectivity according to cheek pouch samples & 2 & $\mathrm{X}$ & 1 \\
\hline 8. Effects and mitigation of oil and gas developments & 2 & $\mathrm{X}$ & 2 \\
\hline 9. Effects and mitigation of military land uses & 2 & $X$ & 2 \\
\hline 10. Effects and mitigation of agricultural practices & 2 & & 2 \\
\hline 11. Effects and mitigation of rural and industrial developments & 2 & & 2 \\
\hline $\begin{array}{l}\text { 12. Hibernation patterns related to diet, weather, disturbances, } \\
\text { population genetics }\end{array}$ & 2 & & 2 \\
\hline 13. Genetic relatedness of local populations & 3 & & 3 \\
\hline 14. Origin and role of the north-Hilda population & 3 & & 3 \\
\hline 15. Alberta population in the context of species' full extent in Canada & 3 & & 3 \\
\hline $\begin{array}{l}\text { 16. Taxonomic identity (i.e., revision of subspecies or species, including } \\
\text { genetic analysis) }\end{array}$ & 3 & & 3 \\
\hline
\end{tabular}




\subsection{APPENDIX 2}

Literature relevant to the status of Ord's kangaroo rats in Alberta and Canada.

Alberta Environment. 2000. First report of the Alberta Endangered Species Conservation Committee. Alberta Environment. Publication No. T/565. 24 pp. Edmonton, AB. [also available at http://www3.gov.ab.ca/srd/fw/escc/pdf/2000_ESCC_Report.pdf]

COSEWIC. 2003. COSEWIC Assessment Results, November 2003. Committee on the Status of Endangered Wildlife in Canada. Ottawa, ON. 44 pp.

Epp, H. T. and L. Townley-Smith. 1980. The Great Sand Hills of Saskatchewan. Saskatchewan Department of the Environment, Regina, SK. 16 pp.

Gummer, D. L. 1995. Status report on the Ord's kangaroo rat (Dipodomys ordii) in Canada. Committee on the Status of Endangered Wildlife in Canada. Ottawa, ON. 27 pp.

Gummer, D. L. 1997a. Effects of latitude and long-term isolation on the ecology of northern Ord's kangaroo rats (Dipodomys ordii). MSc. thesis, University of Calgary. Calgary, AB. $111 \mathrm{pp}$.

Gummer, D.L. 1997b. Ord's kangaroo rat (Dipodomys ordii). Alberta Environment, Wildlife Management Division, Wildlife Status Report No. 4. Edmonton, AB. 16 pp. [also available at http://www3.gov.ab.ca./srd/fw/status/reports/krat/index.html]

Gummer, D. L. and S. E. Robertson. 2003a. Distribution of Ord's kangaroo rats in southeastern Alberta. Alberta Sustainable Resource Development, Fish and Wildlife Division. Species at Risk Report No. 63. Edmonton, AB. 16 pp. [also available at http://www3.gov.ab.ca/srd/fw/speciesatrisk/pdf/SAR 63.pdf]

Gummer, D. L. and S. E. Robertson. 2003b. Evaluation of activities and survival of Ord's kangaroo rats during and post-construction of the North Suffield pipeline. Final report prepared for EnCana Suffield Gas Pipeline Inc. Provincial Museum of Alberta, Edmonton, AB. 43 pp. [also available at http://www.pma.edmonton.ab.ca/natural/mammals/pubs/_pdfs/enca-lo.pdf] 


\subsection{APPENDIX 3}

List of acronyms used.
$\mathbf{A E}=$ Alberta Energy
$\mathbf{B M P}=$ beneficial management practice
BSOD = biodiversity/species observation database
CFB Suffield = Canadian Forces Base Suffield
COSEWIC = Committee on the Status of Endangered Wildlife in Canada
CWS = Canadian Wildlife Service, Environment Canada
DND $=$ Department of National Defence
$\mathbf{E S C C}=$ Endangered Species Conservation Committee
$\mathbf{E U B}=$ Energy and Utilities Board
PFRA = Prairie Farm Rehabilitation Administration
RAM = Royal Alberta Museum
SEAC $=$ Suffield Environmental Advisory Committee
SIRC $=$ Suffield Industry Range Control
SGAC = Suffield Grazing Advisory Committee
SNWA = Suffield National Wildlife Area 


\section{List of Titles in the Alberta Species at Risk Recovery Plan Series}

(as of July 2005)

No. 1 Maintenance and Recovery Plan for Western Blue Flag (Iris missouriensis) in Canada. (2002)

No. 2 Alberta Piping Plover Recovery Plan 2002-2004. (2002)

No. 3 Àlberta Peregrine Falcon Recovery Plan 2004-2010. (2005)

No. 4 Alberta Woodland Caribou Recovery Plan 2004/05-2013/14. (2005) 




1) 